\title{
Estratégias de aprendizagem no Teletandem: o que os aprendizes de língua inglesa afirmam fazer para aprender nesse contexto?
}

\author{
Bruna da Silva Campos \\ Universidade Estadual Paulista "Júlio de Mesquita Filho" \\ silvacampos.bruna@gmail.com \\ Ana Cristina Biondo Salomão \\ Universidade Estadual Paulista "Júlio de Mesquita Filho" \\ ana.salomao@unesp.br
}

\section{Resumo}

As estratégias de aprendizagem vêm sendo pesquisadas na área de ensino e aprendizagem de línguas há muitos anos, uma vez que o foco passou a ser o aluno e não o professor. Muitas pesquisas enfocaram o aprendiz em sala de aula, haja vista que ela era tradicionalmente entendida como um local de excelência para o ensino de línguas. Entretanto, com o advento das tecnologias digitais, surgiram novas ferramentas e modalidades de aprendizagem, como, por exemplo, a telecolaboração a distância orientada pelas relações interculturais. $\mathrm{O}$ contexto dessa pesquisa, o Teletandem, encontra-se diretamente relacionado aos recursos de comunicação síncrona com uso de vídeo e voz, que geram oportunidades de interação oral com falantes da língua alvo em propostas de ensino e aprendizagem a distância. $\mathrm{O}$ objetivo geral desta pesquisa foi investigar quais estratégias de aprendizagem foram utilizadas pelos participantes nas interações de Teletandem. A metodologia de pesquisa e os instrumentos de coleta de dados foram de natureza qualitativa. Os resultados revelaram que os participantes investigados afirmam utilizar principalmente as estratégias de aprendizagem dos tipos sociais e metacognitivas, que se relacionam a dois princípios do Teletandem: reciprocidade e autonomia.

Palavras-chave: Ensino-aprendizagem de línguas; Estratégias de aprendizagem; Telecolaboração; Teletandem; Língua inglesa.

\section{Abstract}

Learning strategies have been researched in the area of language teaching and learning for many years, since the focus has been on the student rather than the 
teacher. A number of investigations have focused on the learner in the classroom, as this has traditionally been the place of excellence for language teaching. However, with the advent of digital technologies, new tools and learning modalities have emerged, for example, distance telecollaboration oriented by intercultural relations. The context of this research, Teletandem, is directly related to synchronous communication tools using video and audio, which generate opportunities for oral interaction with target language speakers in distance teaching and learning proposals. The main objective of this research was to investigate which learning strategies were used by the participants in Teletandem interactions. The research methodology and data collection instruments had qualitative nature. Data analysis revealed that the investigated participants claim to mainly use social and metacognitive learning strategies, which relate to two principles of Teletandem: reciprocity and autonomy.

Keywords: Language teaching and learning; Learning strategies; Telecollaboration; Teletandem; English Language.

\section{Introdução}

Estratégias de aprendizagem vêm sendo pesquisadas na área de ensino e aprendizagem de línguas há muitos anos, uma vez que o foco passou a ser como os alunos aprendem, e não o modo como o professor ensina. Alguns dos mais reconhecidos trabalhos sobre o assunto são Oxford (1990) e O'Malley e Chamot (1990); entretanto, desde a década de 1970, alguns estudos, como Rubin (1975) e Stern (1975), já buscavam compreender o que o "bom aprendiz" fazia para se desenvolver.

Como o local de excelência do ensino de línguas sempre foi tradicionalmente a sala de aula, muitas pesquisas enfocaram o aprendiz nesse contexto. No Brasil, por exemplo, em uma busca no diretório de teses da Capes, usando o termo estratégias de aprendizagem entre aspas, encontram-se 103 trabalhos de mestrado e doutorado na grande área do conhecimento em Linguística, Letras e Artes, sendo a maior parte deles voltados ao estudo das estratégias em contexto presencial.

Mais recentemente, com o advento das tecnologias digitais, surgiram novas ferramentas e modalidades de aprendizagem com uso de recursos de comunicação síncrona e assíncrona de maneira sistemática ou não sistemática dentro e fora da sala de aula. Nesses novos contextos, principalmente os que favorecem a aprendizagem independente, foram 
também investigadas as estratégias usadas pelos aprendizes (HURD; LEWIS, 2008). White (2008), por exemplo, apresenta um panorama das estratégias usadas em contextos de aprendizagem independente como os de imersão e os virtuais. A autora afirma que a agenda de pesquisa é emergente nesse campo, principalmente, porque ainda desconhecemos os processos usados pelos aprendizes nesses novos contextos.

Kern, Ware e Warschauer (2004) sugerem que o atual momento do ensino de línguas mediado por computador seria uma "segunda onda" constituída principalmente pela telecolaboração a distância orientada pelas relações interculturais. Thorne (2006) corrobora essas ideias explicitando a ênfase no ensino de língua envolto em uma estrutura de competência intercultural e pragmática, expandindo-se o contexto de instrução da sala de aula, como atividade local, para interação entre comunidades e nações. $O$ contexto dessa pesquisa encontra-se diretamente relacionado aos recursos de comunicação síncrona com uso de vídeo e voz, que geram oportunidades de interação oral com falantes da língua alvo em propostas de ensino e aprendizagem a distância. O Teletandem (TELLES; VASSALLO, 2006; VASSALLO; TELLES, 2006) é uma modalidade que objetiva colocar pares de falantes de diferentes línguas trabalhando de forma colaborativa, por meio de recursos de comunicação síncrona na internet, como o Skype, para aprenderem a língua um do outro, consistindo em sessões de interação (de 60 minutos) por meio dessa ferramenta. Nessas sessões, os participantes revezam entre o papel de aprendiz da língua estrangeira e de tutor de sua língua materna para seu parceiro, sendo cada trinta minutos da sessão dedicados a cada um desses papéis.

Segundo Aranha e Cavalari (2014), o Teletandem não contribui somente para a aprendizagem de língua estrangeira por meio da oportunidade de desenvolver competências linguístico-comunicativa e cultural, mas se constitui também como um fértil contexto de pesquisa. Uma variedade de temas que vão desde aspectos culturais até relações de poder já foi estudada nesse contexto. Entretanto, poucos trabalhos tratam das estratégias de aprendizagem usadas pelos participantes, principalmente em sessões orais, as quais explicitaremos no decorrer do artigo.

O presente estudo objetivou preencher as seguintes lacunas de pesquisa: (a) mapear quais estratégias de aprendizagem os participantes brasileiros de Teletandem afirmam utilizar para aprender nas sessões 
orais de Teletandem, e (b) verificar, por meio da opinião dos participantes, como essas estratégias auxiliam sua aprendizagem.

Entende-se, como Brown (2007), que se os aprendizes estão conscientes de suas próprias capacidades e limitações, eles podem adotar eficientemente caminhos para o sucesso que capitalizem os pontos fortes e compensem as fraquezas, isto é, a utilização de estratégias de aprendizagem. Assim, buscou-se investigar quais são as estratégias de aprendizagem mencionadas pelos participantes nas interações de Teletandem, as quais eles acreditam contribuir para a sua aprendizagem de língua inglesa nesse contexto. Os resultados serão discutidos de modo a contribuir para: (a) auxiliar outros interagentes e (b) (in)formar mediadores de Teletandem para que compreendam a importância de se fomentar a reflexão sobre as estratégias de aprendizagem nesse contexto.

\section{Teletandem}

O Teletandem constitui-se como uma variedade do tandem a distância na qual se utilizam recursos de áudio e vídeo para comunicação oral, proporcionando o estabelecimento de parcerias, amizades e trocas de informações culturais entre os pares interagentes (TELLES, 2009). Tandem refere-se a uma proposta de aprendizagem colaborativa, sendo essa dimensão explicitada na metáfora que lhe dá nome: tandem é uma palavra inglesa usada para denominar bicicletas de dois assentos (tandem bicycles), ou seja, bicicletas cujo esforço conjunto dos dois ciclistas as colocam em movimento (SOUZA, 2003). No que se refere aos meios pelos quais o tandem é constituído, há o tandem face a face, realizado presencialmente; e o e-tandem, que permite a comunicação entre duas pessoas por meio de troca de e-mails ou chat (SILVA, 2008). Assim, a aprendizagem de línguas em tandem envolve pares falantes de diferentes línguas trabalhando, de maneira colaborativa, para aprenderem a língua um do outro.

Vassallo e Telles (2006), baseando-se em Brammerts (1996), entendem que as interações em Teletandem pautam-se em três princípios: 
a) Separação de línguas: cada língua deve ser utilizada em um período definido da sessão de interação, visando a proporcionar uma exposição equilibrada e a manter o status das línguas da parceria, isto é, cada participante deve comprometer-se a usar a língua estrangeira da qual é aprendiz e a sua língua materna em proporções iguais;

b) Reciprocidade: estabelecimento de uma parceria colaborativa entre as duplas interagentes, na qual ambos estejam comprometidos com a aprendizagem de seu parceiro;

c) Autonomia: cada interagente é responsável pelo gerenciamento do seu próprio processo de aprendizagem, o que lhes possibilita decidir o que, quando, onde e como estudar, assim como quanto tempo eles desejam fazer isso.

A partir do estabelecimento desses princípios, Telles (2006) compreende que a perspectiva de aprendizagem que embasa o Teletandem é a sociointeracionista (VYGOTSKY, 1991). A aprendizagem, nessa perspectiva, ocorre pela interação social mediada pela linguagem, sendo compreendida como uma construção de significados pelo indivíduo.

Há também a previsão de um suporte aos participantes por meio da sessão de mediação, pautada em conceitos vygotskyanos. As sessões de mediação são encontros entre o interagente (aluno universitário praticante de Teletandem) e o mediador (aluno de graduação ou pósgraduação), de modo que possam discutir sobre aspectos relacionados à prática do aluno para, a seguir, refletirem juntos acerca das dúvidas, dos problemas encontrados no ensino e aprendizagem de línguas nas sessões de Teletandem, bem como questões culturais e possíveis impasses (SALOMÃO, 2011).

Para Vygotsky (1991), a relação do homem com o mundo não é uma relação direta, mas uma relação mediada. Em sua teoria, a Zona de Desenvolvimento Proximal (ZDP) é um elemento de grande importância. Ela é entendida como a distância entre o nível de desenvolvimento real - que se costuma determinar por meio da solução independente de problemas - e o nível de desenvolvimento potencial, determinado através da solução de problemas sob a orientação de um adulto ou em colaboração com companheiros mais capazes (VYGOTSKY, 1991). Nesse viés, Salomão (2011, p.20) entende que: 
O termo mediador é usado, desse modo, por estar intimamente ligado às ideias de Vygotsky em sua teoria social do conhecimento, que expõe a possibilidade de o homem, por meio de suas relações sociais e da linguagem, constituir-se e desenvolver-se como sujeito (FREITAS, 2000).

O mediador, no Teletandem, se coloca para o interagente como um parceiro de discussão, fazendo, dessa forma, a intermediação da aprendizagem segundo pressupostos vygotskianos de desenvolvimento por meio da interação social e do oferecimento de andaimes (SALOMÃO, 2012).

De acordo com Telles (2009), em um contexto de ensinoaprendizagem de língua estrangeira mediado pela tecnologia, como o Teletandem, há uma mudança no papel do professor. Primeiramente, ele era visto como detentor do conhecimento e controlador do processo e da velocidade da aprendizagem; já no Teletandem, o professor passa a ser um mediador, um profissional que medeia o ensino-aprendizagem das duplas de aprendizes. O profissional passa, então, a nortear escolhas, usando seus conhecimentos - teóricos e adquiridos na prática docente sobre o ensino-aprendizagem de língua estrangeira com o intuito de gerenciar as dificuldades encontradas pelos interagentes, bem como orientá-los quanto aos processos e estratégias de aprendizagem.

Evangelista e Salomão (2019) explicam que, no Teletandem, a mediação tem sido realizada de diferentes modos, a partir de sessões de reflexão, individuais ou em grupos, e e do uso de diários reflexivos, dialogados ou não. Quando realizadas por meio de diários reflexivos dialogados, como é o caso da pesquisa aqui apresentada, os mediadores, alunos de graduação, de iniciação científica e de pós-graduação que fazem pesquisas nesse contexto, colocam entradas em um ambiente de Moodle com perguntas norteadoras. Os diários são então redigidos pelos interagentes brasileiros, ao final de cada interação, e respondidos pelos mediadores com o intuito de levar o interagente a refletir sobre sua aprendizagem nesse contexto colaborativo e autônomo. Nesse viés, as referidas autoras afirmam que há a necessidade dessas sessões de mediação, uma vez que os interagentes podem não ser capazes de explorar de forma completa o potencial que esse contexto oferece. Logo, por meio da mediação, os participantes podem refletir acerca de seus objetivos, assim como revisá-los, e podem avaliar seu progresso em sua 
aprendizagem. Nesse sentido, Telles e Vassallo (2006) entendem a reflexão após cada sessão de interação como um diferencial do Teletandem quando comparado a um bate-papo informal, pois é um espaço de aprendizagem com foco no desenvolvimento linguísticocultural dos participantes. Os autores compreendem que essa reflexão pode focar conteúdo, cultura, forma, léxico e o processo de interação em si.

Entre os estudos relacionados às estratégias de aprendizagem em contexto (tele)colaborativo, destacamos Braga (2004), enfocando parcerias de tandem via e-mail, e Silva (2008), Luz (2009) e Cavalari (2009), no contexto do Projeto Teletandem Brasil.

Braga (2004) analisou o uso das estratégias dos tipos sociais e de compensação em uma parceria tandem via e-mail entre universitários americanos, estudantes de língua portuguesa, e estudantes brasileiros de inglês de uma escola de idiomas de Belo Horizonte (MG). A autora concluiu, em seu estudo, que o uso dessas estratégias pode auxiliar os aprendizes na construção do conhecimento na língua alvo e que o ambiente virtual promove o desenvolvimento linguístico e da autonomia do estudante.

Silva (2008) realizou um mapeamento do uso das estratégias e suas possíveis implicações para o processamento do insumo de uma língua estrangeira em dados de seis meses de interações in-tandem a distância entre duas interagentes (uma argentina e uma brasileira) que praticavam espanhol/português via chat. A análise dos dados revelou que, por meio do uso das estratégias de aprendizagem, o par interagente participante da pesquisa demonstrou alguns processos de aquisição semelhantes entre si.

Luz (2009) investigou o desenvolvimento da autonomia nas interações de Teletandem por uma análise das estratégias de aprendizagem utilizadas por um par de interagentes (uma brasileira e um estadunidense). A pesquisadora constatou que o par em questão, ao empregar estratégias de aprendizagem nas interações, mostrou-se autônomo.

Um outro estudo foi desenvolvido por Cavalari (2009), que investigou a autoavaliação em tandem via chat entre uma formanda de um curso de licenciatura em Letras e dois interagentes norte-americanos. A autora entende que, no contexto Teletandem, busca-se a promoção da autonomia do aprendiz e que a autoavaliação deve ter um papel crucial 
nesse ambiente, pois permite ao participante refletir acerca de seu próprio processo de aprendizagem e fazer um diagnóstico de seu desempenho, de suas habilidades e das estratégias que usa. Em sua tese, Cavalari (2009) entende que as estratégias de aprendizagem e a metacognição estão em harmonia com a prática autoavaliativa.

Este estudo compartilha com os demais o foco nas estratégias de aprendizagem usadas pelos participantes em contextos telecolaborativos, mas se diferencia pelo enfoque no levantamento das visões dos participantes, no que que tange às estratégias de aprendizagem usadas por eles para aprender em Teletandem, em três diferentes momentos: antes, durante e depois das sessões. É importante mencionar também que, naqueles estudos, as interações de Teletandem ocorriam via chat, enquanto os participantes desta pesquisa realizaram Teletandem por meio de recursos de áudio e vídeo, contando com o uso do chat somente como apoio à conversa durante a interação.

Na próxima seção, discorre-se acerca do segundo aporte teórico deste estudo, as estratégias de aprendizagem.

\section{Estratégias de aprendizagem}

Segundo Williams e Burden (2002), os aprendizes trazem consigo características próprias, individuais, assim como atribuições e percepções acerca de sua aprendizagem. Eles não são passivos nesse processo, ao contrário, eles estão envolvidos em resolver seus problemas para que possam aprender. Ao longo do processo de aprendizagem de língua inglesa, cada aprendiz desenvolve alguma estratégia a fim de auxiliar sua aprendizagem. Por exemplo, enquanto alguns ouvem músicas para aprimorar a compreensão oral e o vocabulário, outros assistem a filmes ou formam grupos de conversação. Para esses autores, as habilidades e estratégias utilizadas são várias operações que os aprendizes usam para fazer sentido em seu aprendizado, referindo-se a ações específicas usadas para responder a determinado problema.

Brown (2007) compreende que as estratégias de aprendizagem são métodos específicos de se abordar um problema ou tarefa, um modo de operação para chegar a um fim particular. Lee (2010) conceitua as estratégias de aprendizagem com uma metáfora, ao afirmar que, quando os estudantes começam a aprender algo, eles têm a habilidade de 
responder a uma situação de aprendizagem particular e de gerenciar esse processo de forma apropriada: "a estratégia de aprendizagem é como jogadores de futebol que usam táticas para ganhar um jogo, quando eles estão em um estádio. Os aprendizes usam as estratégias de aprendizagem para aprender algo com mais êxito" (p. 135) ${ }^{1}$.

Segundo Vilaça (2010), o livro "Language Strategies: what every teacher should know”, de Rebecca L. Oxford (1990), é a obra referência dentro dos estudos sobre as estratégias de aprendizagem, uma vez que combina discussões teóricas acerca delas e orientações para práticas em sala de aula, objetivando identificar as estratégias empregadas por aprendizes e para o ensino das dessas. Oxford tem sido, nos últimos anos, referência para vários pesquisadores que se dedicam ao estudo sobre essas estratégias (SILVA, 2006; SOARES, 2013). A mais inclusiva taxonomia das estratégias de aprendizagem de língua é a de Oxford (LEE, 2010; ZARE, 2012).

Oxford (1990) afirma que as estratégias de aprendizagem são ações específicas tomadas pelo aprendiz para tornar o aprendizado mais fácil, rápido, agradável, autodirigido, eficaz e transferível a novas situações, assim como elas são procedimentos que o aprendiz executa para aprender determinado conteúdo. A pesquisadora dividiu as estratégias de aprendizagem em dois grupos: estratégias diretas e estratégias indiretas. Cada uma dessas se subdivide em três grupos cada: estratégias de aprendizagem diretas (memória, cognitivas e de compensação) e indiretas (metacognitivas, afetivas e sociais). As estratégias diretas de aprendizagem dizem respeito aos processos de aprendizagem, ou seja, como os aprendizes lidam diretamente com a língua de estudo, estando mais relacionadas ao input da língua (BROWN, 2007). Já as estratégias indiretas de aprendizagem relacionam-se à gestão da aprendizagem, que se refere ao aprendiz ser o responsável pelo seu processo de aprendizagem.

De acordo com Oxford (1990), as estratégias de memória possibilitam ao aprendiz guardar as novas informações sobre a línguaalvo. As estratégias cognitivas são essenciais na aprendizagem de uma nova língua, sendo vistas como um processo mental diretamente

\footnotetext{
${ }^{1}$ No original " $[\ldots]$ learning strategy is like footballers who use tactics in order to win a game, when they are in the stadium. Learners use learning strategies in order to learn something more successfully" (LEE, 2010, p. 135).
} 
interessado ao processamento da informação, para que se aprenda, permitindo ao aprendiz consolidar, elaborar e transformar o conhecimento da língua e da cultura (OXFORD, 2011, 2014). Já as estratégias de compensação, de acordo com a autora, permitem ao aluno utilizar a língua mesmo que não a conheça suficientemente. Elas possibilitam que, embora haja limitações ou problemas de conhecimento, os aprendizes utilizem a língua tanto para a compreensão quanto para a produção linguística.

As estratégias metacognitivas, segundo Oxford (1990), incluem a habilidade de gerenciar e regular conscientemente o uso de estratégias de aprendizagem adequadas para diferentes situações. Essas estratégias envolvem o planejamento, a organização, o monitoramento e a avaliação da aprendizagem, ajudando no controle desse processo pelo estudante (OXFORD, 2011, 2014). No que se referem às estratégias afetivas, aspectos como emoção, atitudes, motivação e valores influenciam a aprendizagem da língua. Segundo Oxford (2011), essas estratégias ajudam o estudante a criar emoções e atitudes positivas e a se sentir motivado em sua aprendizagem. As estratégias sociais permitem ao aprendiz aprender a língua por meio da interação e da colaboração com os demais, sejam eles aprendizes ou falantes da língua. Essas estratégias evidenciam a língua como forma de comportamento social que ocorre entre duas ou mais pessoas. Alguns exemplos das estratégias sociais são: fazer perguntas, pedir esclarecimentos e/ou correções, cooperar com os outros, praticar a língua com os demais alunos, aprender a cultura do país da língua alvo, entre outros.

O’Malley e Chamot (1990) compreendem as estratégias de aprendizagem como pensamentos ou comportamentos especiais que os aprendizes utilizam a fim de ajudá-los a compreender, aprender ou reter nova informação, sendo formas especiais do processamento de informações que melhoram a compreensão, a aprendizagem, ou a retenção delas. Esses pesquisadores classificam as estratégias de aprendizagem diferentemente de Oxford (1990), estruturando-as em apenas três tipos: cognitivas, metacognitivas e socioafetivas.

a) Estratégias cognitivas: são estratégias que se referem à manipulação do material de aprendizagem. O'Malley e Chamot (1990), assim como Oxford (1990, 2011, 2014), entendem que repetição, tradução, tomar notas, dedução, uso de palavras- 
chave também são exemplos desse tipo de estratégia. Oxford, entretanto, as coloca divididas em três subcategorias em sua taxonomia (memória, cognitiva e de compensação);

b) Estratégias metacognitivas: assim como Oxford (1990, 2011, 2014), O'Malley e Chamot (1990) entendem que esse tipo de estratégia envolve o planejamento para aprender, pensar a respeito do processo de aprendizagem e como ele ocorre, por meio da (auto)observação da produção e/ou compreensão, corrigindo os seus erros e avaliando a aprendizagem depois de uma atividade completa. Segundo os referidos autores, organização, atenção direcionada, atenção seletiva, autogerenciamento, planejamento funcional, autocontrole e autoavaliação são as principais estratégias metacognitivas;

c) Estratégias socioafetivas: diferentemente de Oxford (1990), que separa estratégias sociais e afetivas, O’Malley e Chamot (1990) as agrupam sob a denominação "estratégias socioafetivas". A principal estratégia socioafetiva, para esses autores, é a cooperação.

A seguir, trata-se da metodologia que fundamentou a análise de dados. Para a análise de dados, optou-se por unir as duas taxonomias, a de Oxford (1990) e a de O’Malley e Chamot (1990), uma vez que se entende que elas se relacionam, pois apresentam categorizações semelhantes.

\section{Metodologia}

A presente pesquisa caracteriza-se como qualitativa, uma vez que, segundo Minayo (2004), ela responde questões muito particulares com um nível de realidade que não pode ou não deveria ser quantificado, tendo em vista que trabalha com o universo dos significados, dos motivos, das aspirações, das representações, dos valores e das atitudes. Além disso, este estudo é qualitativo, porque objetiva entender o contexto de pesquisa baseando-se na perspectiva de seu interior, como explicado por Burns (1999): 
O alvo da abordagem qualitativa é oferecer descrições, interpretações e esclarecimentos de contextos sociais naturais (...) a pesquisa qualitativa utiliza dados coletados pelo pesquisador para entender o comportamento humano dentro do contexto de pesquisa2 (BURNS, 1999, p. 22).

Compreende-se também que este estudo tem natureza interpretativista, pois a visão das pesquisadoras será considerada como parte integrante da construção do conhecimento, uma vez que elas interpretam os fenômenos, e, a partir de seu ponto de vista, atribuemlhes significado (MOITA LOPES, 1994). A coleta de dados foi realizada durante as interações de Teletandem de língua inglesa e língua portuguesa no Laboratório de Idiomas da Faculdade de Ciências e Letras de Araraquara. Os dados foram coletados entre os dias 17 de outubro de 2016 e 21 de novembro de 2016.

A investigação contou com 14interagentes brasileiros, estudantes de graduação e pós-graduação, que realizaram Teletandem de língua inglesa com alunos de uma universidade norte-americana no segundo semestre de 2016. Entre eles, 12 eram do sexo feminino e dois do sexo masculino. A faixa etária dos interagentes era entre 17 e 23 anos de idade, perfazendo uma média de 20 anos de idade.

Segundo Chamot (2005), para identificar as estratégias de aprendizagem, pode-se utilizar de alguns instrumentos de pesquisa como, por exemplo, questionários e diários escritos pelos alunos. Assim, com o objetivo de investigar quais foram as estratégias de aprendizagem mencionadas pelos participantes brasileiros do Teletandem que contribuíram para a sua aprendizagem em língua inglesa nesse contexto, optou-se por utilizar os seguintes instrumentos de coleta de dados:

${ }^{2}$ No original "The aim of qualitative approaches it to offer descriptions, interpretations and clarifications of naturalistic social contexts (...) qualitative research draws on the data collected by the researcher to make sense of the human behavior within the research context (BURNS, 1999, p. 22). 
Quadro 1-Instrumentos de pesquisa e suas finalidades

\begin{tabular}{|c|l|}
\hline $\begin{array}{c}\text { Instrumento } \\
\text { de pesquisa }\end{array}$ & \multicolumn{1}{|c|}{ Finalidade } \\
\hline $\begin{array}{c}\text { QUESTIONARIO } \\
\text { INICIAL }\end{array}$ & $\begin{array}{l}\text { Obter dados sobre os participantes brasileiros, suas } \\
\text { experiências e histórias acerca de sua aprendizagem em } \\
\text { língua inglesa, e detectar as possíveis estratégias de } \\
\text { aprendizagem que poderiam ser usadas nas interações. }\end{array}$ \\
\hline $\begin{array}{c}\text { DIARIOS } \\
\text { REFLEXIVOS }\end{array}$ & $\begin{array}{l}\text { Encontrar relatos das estratégias de aprendizagem usadas } \\
\text { por eles durante as sessões. }\end{array}$ \\
\hline QUESTIONÁRIO & $\begin{array}{l}\text { Corroborar as perspectivas iniciais com as finais dos } \\
\text { participantes da pesquisa frente a sua participação no } \\
\text { Teletandem. Analisar se o que foi respondido nesse } \\
\text { momento, de forma geral, vai ao encontro dos achados } \\
\text { dos demais instrumentos de coleta de dados. }\end{array}$ \\
\hline
\end{tabular}

Fonte: Elaboração própria

Os dados coletados a partir desses instrumentos foram analisados com o propósito de levantar os marcadores (palavras-chave) de maior recorrência e que remetiam a alguma estratégia de aprendizagem mencionada pelos participantes deste estudo antes, durante e após o término das sessões de Teletandem, por meio de cada instrumento respectivamente.

Com base em Burns (1999), a triangulação dos dados foi realizada, trazendo dados oriundos de diferentes instrumentos de pesquisa, de modo a confrontar e entrecruzar suas informações. Assim, através da triangulação dos dados neste estudo, pretendeu-se analisar como as estratégias de aprendizagem foram explicitadas pelos participantes nos três diferentes momentos da coleta de dados: (1) antes do início do Teletandem, com o questionário inicial; (2) durante as sessões de Teletandem, por meio dos diários reflexivos; e (3) após as sessões de Teletandem, com o questionário final.

No quadro 2, a seguir, apresenta-se o modo como foi realizada a categorização dos dados. Na primeira coluna, estão as estratégias de aprendizagem, baseadas na taxonomia de Oxford $(1990,2011,2014)$ e O’Malley e Chamot (1990). Na segunda e terceira colunas, encontra-se uma compilação das principais palavras-chave que se relacionavam com 
cada uma das estratégias e exemplo de como foram encontradas no corpus.

\section{Quadro 2 - Categorização dos tipos de estratégias de aprendizagem}

\begin{tabular}{|c|c|c|}
\hline Tipo de estratégia & Palavras-chave & Exemplo \\
\hline $\begin{array}{ll}\text { COGNITIVA } & \\
\text { (OXFORD, } & 1990, \\
\text { 2011, } & 2014, \\
\text { O'MALLEY; } \\
\text { CHAMOT, 1990) } \\
\end{array}$ & $\begin{array}{l}\text { - Anotar / tomar nota; } \\
\text { - Procurar; } \\
\text { - Assistir; } \\
\text { - Ouvir / escutar. }\end{array}$ & $\begin{array}{l}\text { No Teletandem, pretendo anotar } \\
\text { as palavras novas, procurar } \\
\text { significados, criar frases e } \\
\text { utilizá-las em minhas interações. }\end{array}$ \\
\hline $\begin{array}{l}\text { COMPENSAÇÃO } \\
\text { (OXFORD, 1990) }\end{array}$ & $\begin{array}{l}\text { - Gesticular; } \\
\text { - Linguagem / } \\
\text { expressão corporal; } \\
\text { - Movimentos. }\end{array}$ & $\begin{array}{l}\text { Olhar os movimentos da pessoa } \\
\text { para ajudar a distinguir palavras } \\
\text { com som semelhante. }\end{array}$ \\
\hline $\begin{array}{l}\text { METACOGNITIVA } \\
\text { (OXFORD, 1990, } \\
\text { 2011, 2014, } \\
\text { O'MALLEY; } \\
\text { CHAMOT, 1990) }\end{array}$ & $\begin{array}{l}\text { - Verificar; } \\
\text { - Melhorar; } \\
\text { - Superar; } \\
\text { - Perceber / ver / } \\
\text { notar; } \\
\text { - Acreditar / achar (no } \\
\text { sentido de avaliar); } \\
\text { - Planejar / pretender; } \\
\text { - Precisar; } \\
\text { - Avaliar; } \\
\text { - Objetivo. }\end{array}$ & $\begin{array}{l}\text { Tenho o objetivo de saber o } \\
\text { quanto posso falar e } \\
\text { compreender a língua inglesa } \\
\text { numa conversa formal com um } \\
\text { nativo. }\end{array}$ \\
\hline $\begin{array}{l}\text { SOCIAL } \\
\text { (OXFORD, 1990) }\end{array}$ & $\begin{array}{l}\text { - Perguntar / } \\
\text { questionar; } \\
\text { - Conversar; } \\
\text { - Ajudar; } \\
\text { - Pedir; } \\
\text { - Corrigir; } \\
\text { - Explicar; } \\
\text { - Contribuir; } \\
\text { - Ensinar; } \\
\text { - Auxiliar; } \\
\text { - Combinar; } \\
\text { - Praticar. }\end{array}$ & $\begin{array}{l}\text { Na interação oral, aprendo novas } \\
\text { palavras perguntando ao meu } \\
\text { interlocutor. }\end{array}$ \\
\hline $\begin{array}{l}\text { MEMÓRIA } \\
\text { (OXFORD, 1990) }\end{array}$ & $\begin{array}{l}\text { - Imagem; } \\
\text { - Som; } \\
\text { - Rima; } \\
\text { - Palavra (s) - chave; } \\
\text { - Memorizar. } \\
\end{array}$ & $\begin{array}{l}\text { Aprendo palavras assistindo } \\
\text { filmes, série e ouvindo músicas. } \\
\text { Com as palavras que conheço } \\
\text { nessas mídias, eu faço fichas } \\
\text { com desenho para memorização. }\end{array}$ \\
\hline
\end{tabular}

Fonte: Elaboração própria 
A categorização apresentada nesse quadro foi realizada por meio de um levantamento dos vocábulos mais recorrentes nos instrumentos de coleta de dados, ou seja, no discurso dos participantes de pesquisa, cujo sentido remetesse a alguma das estratégias de aprendizagem, conforme pode-se observar na coluna de exemplos.

Na próxima seção, apresenta-se a análise e discussão dos dados.

\section{Análise e discussão de dados}

Com o intuito de apresentar um panorama das estratégias encontradas nos dados, expõe-se, neste momento, o quadro 3 mostrando quais foram as estratégias encontradas em cada instrumento e a porcentagem mencionada de cada categoria, para então discutir sua ocorrência em cada momento vivenciado pelos participantes no Teletandem.

Como se observa no quadro, ao analisar as estratégias cognitivas de aprendizagem nos três instrumentos de coleta de dados, ela aparece mais no questionário inicial, momento no qual os participantes ainda projetavam suas expectativas para a aprendizagem no Teletandem, como ilustrado no excerto a seguir:

Excerto 1

Poderemos combinar conjuntamente a melhor forma de aprendizagem para ambos, podendo ser por meio de revistas, jornais, música, filmes, fotos, sites etc. (questionário inicial) 
Estratégias de aprendizagem no Teletandem...

Quadro 3-Estratégias de aprendizagem antes, durante e após o Teletandem

\begin{tabular}{|c|c|c|c|c|}
\hline ESTRATÉGIA & $\begin{array}{l}\text { Questionário } \\
\text { inicial }\end{array}$ & $\begin{array}{l}\text { Diários } \\
\text { reflexivos }\end{array}$ & $\begin{array}{l}\text { Questionário } \\
\text { final }\end{array}$ & $\begin{array}{l}\text { Porcentagem } \\
\text { de menções }\end{array}$ \\
\hline Cognitiva & $\begin{array}{l}\text { Anotar, } \\
\text { procurar } \\
\text { palavras } \\
\text { novas, buscar } \\
\text { no dicionário, } \\
\text { filmes, séries, } \\
\text { músicas, } \\
\text { traduções, } \\
\text { revistas, } \\
\text { jornais. }\end{array}$ & $\begin{array}{l}\text { Não foi } \\
\text { encontrada } \\
\text { nenhuma } \\
\text { palavra-chave } \\
\text { desta } \\
\text { estratégia } \\
\text { neste } \\
\text { instrumento } \\
\text { de pesquisa. }\end{array}$ & Anotar. & $15 \%$ \\
\hline Compensação & $\begin{array}{l}\text { Gestos, } \\
\text { "gesticulação" } \\
\text {, linguagem } \\
\text { corporal, } \\
\text { movimentos, } \\
\text { expressões } \\
\text { corporais. }\end{array}$ & $\begin{array}{l}\text { Não foi } \\
\text { encontrada } \\
\text { nenhuma } \\
\text { palavra-chave } \\
\text { desta } \\
\text { estratégia } \\
\text { neste } \\
\text { instrumento } \\
\text { de pesquisa. } \\
\end{array}$ & $\begin{array}{l}\text { Não foi } \\
\text { encontrada } \\
\text { nenhuma } \\
\text { palavra-chave } \\
\text { desta } \\
\text { estratégia } \\
\text { neste } \\
\text { instrumento } \\
\text { de pesquisa. } \\
\end{array}$ & $10 \%$ \\
\hline Metacognitiva & $\begin{array}{l}\text { Verificar, } \\
\text { melhorar, } \\
\text { superar, } \\
\text { acreditar, } \\
\text { avaliar, } \\
\text { objetivo. }\end{array}$ & $\begin{array}{l}\text { Perceber, } \\
\text { acreditar, } \\
\text { avaliar, } \\
\text { pretender, } \\
\text { melhorar, } \\
\text { notar. }\end{array}$ & $\begin{array}{l}\text { Acreditar/acha } \\
\text { r, ver, } \\
\text { perceber, } \\
\text { avaliar, notar. }\end{array}$ & $32 \%$ \\
\hline Social & $\begin{array}{l}\text { Perguntar, } \\
\text { corrigir. }\end{array}$ & $\begin{array}{l}\text { Perguntar, } \\
\text { auxílio, } \\
\text { explicação, } \\
\text { corrigir. }\end{array}$ & Perguntar. & $41 \%$ \\
\hline Memória & $\begin{array}{l}\text { Fichas com } \\
\text { desenho para } \\
\text { memorização. }\end{array}$ & $\begin{array}{l}\text { Não foi } \\
\text { encontrada } \\
\text { nenhuma } \\
\text { palavra-chave } \\
\text { desta } \\
\text { estratégia } \\
\text { neste } \\
\text { instrumento } \\
\text { de pesquisa. }\end{array}$ & $\begin{array}{l}\text { Não foi } \\
\text { encontrada } \\
\text { nenhuma } \\
\text { palavra-chave } \\
\text { desta } \\
\text { estratégia } \\
\text { neste } \\
\text { instrumento } \\
\text { de pesquisa. }\end{array}$ & $2 \%$ \\
\hline Total & & & & $100 \%$ \\
\hline
\end{tabular}

Fonte: Elaboração própria 
Quando o interagente menciona que a melhor forma de aprendizagem para o par poderia ser pelo uso/pela leitura de revistas e jornais, de músicas, de filmes, de fotos e de sites, ele recorre às estratégias cognitivas de aprendizagem, que, nesses exemplos, podem auxiliar no processamento das novas informações recebidas nas interações. É interessante notar que, ao afirmar que a dupla poderá combinar em conjunto a melhor forma de aprender, o interagente utiliza também a estratégia social de aprendizagem, tendo em vista que ele visa colaborar com seu interagente e se responsabiliza não apenas por sua aprendizagem, mas também pela de seu parceiro. Isso provavelmente se deve ao seu entendimento dessa modalidade de aprendizagem que tem como base a colaboração.

Ao comparar os marcadores presentes no questionário inicial com os do questionário final, percebe-se que estratégias mencionadas antes das interações não apareceram nas respostas dos interagentes após o término das sessões, como, por exemplo, o uso de filmes, séries, músicas para se aprender a língua alvo. Entretanto, há uma menção à estratégia de anotar as informações novas, que também aparecia no questionário inicial. Não foi encontrada nos diários reflexivos nenhuma palavra-chave que remetesse ao uso de estratégia cognitiva. Acredita-se que isso tenha ocorrido pelo fato de que apenas duas das cinco entradas de diários - disponibilizadas para os participantes registrassem suas reflexões - continham questões que poderiam conduzi-los a fornecer dados que remetessem a esta estratégia, ou seja, não indica necessariamente que ela não foi utilizada. Por se tratar de um contexto colaborativo, nota-se que as estratégias ligadas à interlocução com o parceiro, como as sociais, se sobressaem nos relatos.

As estratégias de compensação foram apenas encontradas no questionário inicial, quando os interagentes responderam à seguinte pergunta: "Quais as estratégias que você utiliza para compreender a fala de um falante estrangeiro?". Os participantes afirmaram que observar gestos e linguagem corporal, por exemplo, os auxiliavam a compreender o que um falante estrangeiro estava falando. Considera-se que esse tipo de estratégia pode não ter tido marcadores nos demais instrumentos de pesquisa, pois os parceiros do exterior podem ter ajudado os interagentes brasileiros de outras maneiras como, por exemplo, compartilhando imagens via Skype, e, assim, não foi preciso utilizar alguma estratégia 
desse tipo; ou, também, que os instrumentos de pesquisa não foram capazes de suscitar esse tipo de resposta.

Já as estratégias metacognitivas foram encontradas nos três instrumentos de coleta de dados; portanto, os interagentes - desde o questionário inicial, passando pelos diários reflexivos e chegando até o questionário final - afirmaram que suas estratégias incluíam avaliar seu processo de aprendizagem e estipular metas e objetivos, não somente nas/para as sessões de interação, mas também após o seu término, considerando ser necessário continuar praticando e estudando a língua inglesa, haja vista que a maioria dos participantes é estudante de Letras, como se pode observar nos seguintes excertos:

\section{Excerto 2}

[meu objetivo no Teletandem é] verificar meu entendimento e minha capacidade de me expressar no idioma, melhorando, sobretudo minha pronúncia. (questionário inicial)

\section{Excerto 3}

Tenho notado algumas dificuldades no meu inglês, mas com mais interações, pretendo melhorar. (diário reflexivo 3)

\section{Excerto 4}

Eu pude treinar melhor o ouvir em inglês e compreender, e também a falar mais fluente, mas ainda há muito o que melhorar. (questionário final)

Logo, as estratégias metacognitivas de aprendizagem mencionadas antes, durante e após o Teletandem são coincidentes, uma vez que têm as mesmas palavras recorrentes (como, nos exemplos acima, o verbo "melhorar"). Isso demonstra que os participantes utilizavam de estratégias metacognitivas antes das interações, que também foram incorporadas e adaptadas por meio de suas experiências nesse contexto.

As estratégias sociais de aprendizagem também foram mencionadas pelos interagentes nos três instrumentos de coleta de dados. Neles (questionário inicial, diários reflexivos e questionário final), foram citadas estratégias características desse tipo como: perguntar algo ao parceiro estrangeiro, pedir correção/auxílio para seu interagente, conforme pode-se verificar a seguir: 


\section{Excerto 5}

No Teletandem, posso aumentar meu vocabulário, perguntando o que significa determinada palavra que ele [parceiro interagente] disse ou como se fala uma palavra na língua dele (questionário inicial).

\section{Excerto 6}

Pretendo no momento que não entender algo, pedir para o outro participante escrever, e então, pedir um sinônimo (diário reflexivo 4).

\section{Excerto 7}

Quando o meu parceiro dizia alguma palavra que eu não conhecia, eu perguntava o que ele queria dizer, e assim aprendia novas palavras (questionário final).

Pode-se afirmar que o alto índice de recorrência das estratégias sociais, principalmente nos dados advindos dos diários, que foram escritos no decorrer do período das sessões, pode estar relacionado a um dos princípios do Teletandem: a reciprocidade. Nas interações de Teletandem, deve haver uma relação colaborativa entre o par de interagentes, na qual, ambos, simultaneamente, são responsáveis pela sua aprendizagem e igualmente responsáveis pela aprendizagem de seu parceiro (SALOMÃO; SILVA; DANIEL, 2009). Entende-se que, para que isso ocorra, é fundamental que os aprendizes estejam dispostos a se engajar no processo comunicativo e a colaborar com os seus desenvolvimentos linguístico e cognitivo reciprocamente (SILVA, 2006). Assim, acredita-se que o uso das estratégias sociais de aprendizagem nesse contexto está intimamente ligado à possibilidade de interação entre os aprendizes, uma vez que eles trabalham em conjunto a fim de melhorar as habilidades comunicativas.

A estratégia de memória apenas foi encontrada no questionário inicial, por meio das perguntas: "Como você geralmente aprende palavras novas em língua inglesa? Como pensa que poderá fazer isso no Teletandem?" Um interagente respondeu que elabora fichas com desenhos para memorizar palavras novas em inglês. Possivelmente, esse participante possa ter utilizado esse tipo de estratégia ao longo das interações, embora isso não tenha sido citado nos diários reflexivos, nem 
no questionário final. A falta de marcadores nesses dois últimos instrumentos pode ter ocorrido pelo fato de os aprendizes não saberem que memorizar, usar rimas e imagens são um tipo de estratégia - logo, eles não registraram essas informações em suas reflexões e respostas ou pelo fato de eles não terem, de fato, utilizado esses recursos em sua aprendizagem de língua inglesa em Teletandem.

De modo geral, percebe-se que alguns dados demonstram que questões ligadas à afetividade e à emoção podem ser tratadas nas parcerias de Teletandem, como é possível verificar nos excertos a seguir:

\section{Excerto 8}

Espero desenvolver a conversação e me sentir mais confiante. (questionário inicial).

\section{Excerto 9}

Quero aprimorar minha habilidade de fala na língua e desenvolver a confiança na hora de me comunicar com um falante nativo da língua. (questionário inicial).

\section{Excerto 10}

Melhorar meu nível de speaking e perder a timidez. (questionário inicial).

Acredita-se que a situação de interação promovida pelo contexto do Teletandem favorece aspectos socioafetivos, pois os participantes estão aprendendo/praticando a língua um do outro, o que pode levá-los a se sentir mais confortáveis. Uma vez que há a troca de papéis entre eles, ambos são aprendizes e tutores, pois em um momento praticam a língua que estão aprendendo e, no outro, ajudam seu parceiro a aprender a sua língua, configurando-se como uma situação diferente da sala de aula.

No questionário final, os participantes afirmaram que, por meio de suas experiências no Teletandem, ganharam não somente mais confiança, mas também autoestima e felicidade, assim como passaram a ter menos medo de errar e a se sentir sem tensão para conversar com um falante de outra língua, como pode-se observar nos excertos abaixo: 


\section{Excerto 11}

A gente não sente aquela tensão de ser uma aula de línguas, temos menos medo de errar e podemos tirar dúvidas livremente com nossos parceiros. (questionário final).

\section{Excerto 12}

Eu me sinto muito mais confiante para conversar e isso foi um aspecto que me deixa muito feliz, consegui trabalhar a minha autoestima. (questionário final).

\section{Excerto 13}

Acho que o Teletandem foi uma ótima maneira de perder a minha timidez, que muitas vezes é o que me leva a ficar nervosa e não conseguir compreender ou lembrar alguma palavra em inglês. (questionário final).

Nos excertos anteriores, os interagentes afirmaram que, por meio das interações, houve melhoras em aspectos emocionais, como no aumento de confiança e autoestima e perda de timidez para se comunicar na língua estrangeira. Acredita-se que isso ocorreu pelo fato desses interagentes serem auxiliados por seus parceiros, que na visão dos nossos interagentes não iam avaliá-los e julgá-los frente a erros e dificuldades, mas sim os ajudariam. Portanto, as expectativas frente às questões emocionais foram confirmadas ao final das interações de Teletandem.

Nos diários reflexivos não foi encontrada nenhuma palavrachave que remetesse à questões socioafetivas, embora nas entradas dos diários $02(24 / 10 / 2016)$ e $03(31 / 10 / 2016)$ - na qual os mediadores sugeriam questões para reflexão - houvesse uma pergunta que poderia conduzir os respondentes a mencionar aspectos socioafetivos nas interações ("Você se sente mais confortável para falar na língua alvo?"). Compreende-se que isto possa ter acontecido por três motivos: (1) porque os alunos não se sentiam cômodos para responder a essa questão naquele momento; (2) porque não se atentaram a ela quando leram as entradas, uma vez que havia várias questões reflexivas sugeridas; (3) porque talvez esse tipo de reflexão seja mais comum ao fim das interações, quando se olha para o todo o percurso, e não durante.

Salienta-se que parece ser importante que os mediadores discutam o uso de estratégias de aprendizagem tanto dentro quanto fora 
do contexto de Teletandem, como, por exemplo, nas aulas da graduação e na futura prática docente da maioria dos participantes de pesquisa (alunos do curso de Letras). Por meio da formulação das questões propostas nos diários reflexivos pelos mediadores, os interagentes podem ser auxiliados a pensar acerca de suas próprias estratégias de aprendizagem e de como elas influenciam sua aprendizagem nesse contexto autônomo e colaborativo. Ademais, como muitas sessões de mediação vêm também sendo realizadas atualmente por meio de rodas de conversa, entende-se que as discussões sobre as estratégias usadas pelos participantes poderão estimulá-los a (re)conhecer novas formas aprender e implementá-las durante as sessões.

\section{Considerações finais}

Em relação às estratégias de aprendizagem no Teletandem, os resultados mostraram que foram citadas as estratégias cognitivas, de compensação, metacognitivas, sociais e de memória pelos participantes como elementos que os auxiliam nas sessões de Teletandem. Entre essas estratégias, as estratégias sociais e metacognitivas foram as mais mencionadas pelos interagentes. Compreende-se que esse fato possa ter ocorrido tendo em vista que essas estratégias se relacionam a dois princípios do Teletandem: reciprocidade e autonomia.

Pelo princípio da reciprocidade, compreende-se que deva existir uma relação colaborativa entre o par interagente, de forma que ambos sejam responsáveis não apenas por sua própria aprendizagem, mas também pela aprendizagem de seu parceiro (SALOMÃO; SILVA; DANIEL, 2009). Entende-se que as estratégias sociais podem conduzir os interagentes a esse princípio, uma vez que, nas sessões de Teletandem, pressupõe-se que haja colaboração e que os interagentes estejam conscientes do contexto colaborativo em que estão inseridos, auxiliando e sendo auxiliados por seus parceiros para que ambos tenham êxito em sua aprendizagem.

Já pelo princípio da autonomia, considera-se que ela é "central não apenas para o resultado/produção, mas também para o processo de aprendizagem. A aprendizagem autônoma depende do desenvolvimento da capacidade de reflexão (metacognição)" (SALOMÃO; SILVA; DANIEL, 2009, p. 81), ou seja, por meio do uso de estratégias 
metacognitivas, que envolvem o estabelecimento de metas e objetivos, prática da autoavaliação e automonitoramento, o interagente pode tornar-se autônomo em sua aprendizagem nas interações de Teletandem. Além disso, os princípios de reciprocidade e de autonomia no Teletandem se relacionam, visto que eles estão intimamente ligados, pois a autonomia não é vista sem o outro, mas sim com e em colaboração com o parceiro.

Por fim, considera-se que a discussão sobre o uso de estratégias seja explicitamente enfocada nas sessões de mediação, por meio dos diários ou das rodas de conversa a fim de que os alunos possam socializar as estratégias usadas e descobrir outras que podem ser incluídas em sua prática de interação com o parceiro. Compreende-se que os mediadores, ao conhecerem as estratégias empregadas pelos interagentes, podem saber como eles aprendem e, assim, melhor auxiliálos no momento de propor reflexões sobre a aprendizagem no contexto de Teletandem.

\section{Referências}

ARANHA, S.; CAVALARI, S.M.S. A trajetória do projeto teletandem Brasil: da modalidade institucional não-integrada à institucional integrada. The Especialist (PUCSP), v. 35, p. 70-88, 2014.

BRAGA, J. C. F. Aprendizagem de línguas em regime de tandem via email: colaboração, autonomia e estratégias sociais. 152f. Dissertação (Mestrado em Linguística Aplicada) - Faculdade de Letras da UFMG, Universidade Federal de Minas Gerais, Belo Horizonte, 2004.

BRAMMERTS, H. Tandem language learning via the internet and the International E-Mail Tandem Network. In Little, David; Brammerts, $\mathrm{H}$. (Eds.) A Guide to Language Learning in Tandem via the Internet. CLCS Occasional Paper, 46, 1996.

BROWN, D. H. Styles and strategies. In: (org.). Principles of language learning and teaching. New York: Pearson Education, p.118151, 2007. 
Estratégias de aprendizagem no Teletandem...

. Teaching by principles: an interactive approach to language pedagogy. New York: Pearson Education, 2007, 569p.

BURNS, A. Collaborative research for English language teachers. Cambridge: Cambridge University Press, 1999.

CAVALARI, S. M. S. A auto-avaliação em um contexto de ensinoaprendizagem de línguas em tandem via chat. 2009. 243f. Tese (Doutorado em Estudos Linguísticos) - Instituto de Biociências, Letras e Ciências Exatas da Universidade Estadual Paulista, UNESP, São José do Rio Preto, 2009.

CHAMOT, A. U. Language learning strategy instruction: current issues and research. Annual review of Applied Linguistics, v.25, EUA: Cambridge University Press, p.112-130, 2005.

EVANGELISTA, M.C.R.G.; SALOMÃO, A.C.B. Mediation in Teletandem. PANDAEMONIUM GERMANICUM, v. 22, p. 153-177, 2019.

HURD, S.; LEWIS, T. Language learning strategies in independent settings. Bristol: Multilingual Matters, 2008.

KERN, R.; WARE, P.; WARSCHAUER, M. Crossing Frontiers: New Directions in Online Pedagogy and Research. Annual Review of Applied Linguistics, v. 24, n. 1, p. 243-260, 2004.

LEE, C. K. An overview of language learning strategies. ARECLS, v. 7, p.132-152, 2010.

LUZ, E. B. P. A autonomia no processo de ensino e aprendizagem de línguas em ambiente virtual (Teletandem). 2009. 279f. Dissertação (Mestrado em Estudos Linguísticos) - Instituto de Biociências, Letras e Ciências Exatas da Universidade Estadual Paulista, UNESP, São José do Rio Preto, 2009.

MINAYO, Maria Cecília de Souza (Org.). Pesquisa social: teoria, método e criatividade. 23. ed. Petrópolis, RJ: Vozes, 2004. 
MOITA LOPES, L. P. Pesquisa interpretativista em Lingüística Aplicada: a linguagem como condição e solução. DELTA, v. 10, n. 2, p. 329-338, 1994.

O’MALLEY, J. M.; CHAMOT, A. U. Learning strategies in second language acquisition. Georgetown: Oxford University, 1990.

OXFORD, R. L. Language learning strategies: what every teacher should know. Boston: Heinle \& Heinle, 1990.

OXFORD, R. L. Teaching and researching language learning strategies. New York: Routledge, 2011.

OXFORD, R. L. et al. The learning strategy prism: Perspectives of learning strategy experts. System, v. 43, p. 30-49, 2014.

RUBIN, J. What the 'good language learner' can teach us. TESOL Quarterly, v. 9, p. 41-51, 1975.

SALOMÃO, A. C. B. A cultura e o ensino de língua estrangeira: perspectivas para a formação continuada no Projeto Teletandem Brasil. 2012. 270f. Tese (Doutorado em Estudos Linguísticos) - Instituto de Biociências, Letras e Ciências Exatas da Universidade Estadual Paulista, UNESP, São José do Rio Preto.

- A formação do formador de professores: perspectivas de colaboração entre graduandos e pós-graduandos no projeto Teletandem Brasil. Revista Brasileira de Linguistica Aplicada, v. 11, n. 3, p. 653677, 2011.

SALOMÃO, A. C. B.; SILVA, A. C.; DANIEL, F. G. A aprendizagem colaborativa in-tandem: Um olhar sobre seus princípios. In: JOÃO A. TELLES. (Org.). Teletandem: um contexto virtual, autônomo e colaborativo para a aprendizagem de línguas no século XXI. 1ed. Campinas: Pontes, 2009, p. 75-92.

SILVA, A. C. O desenvolvimento intra-interlinguístico in tandem a distância (Português e Espanhol). 2008. 358f. Dissertação (Mestrado em Estudos Linguísticos) - Instituto de Biociências, Letras e Ciências 
Estratégias de aprendizagem no Teletandem...

Exatas da Universidade Estadual Paulista, UNESP, São José do Rio Preto, 2008.

SILVA, G. B. A. Estratégias de aprendizagem na aula de língua estrangeira: um estudo com formandos em Letras. 2006. 125 p. Dissertação (Mestrado em Estudos Linguísticos) - Universidade Federal de Santa Maria, Santa Maria, 2006.

SOARES, C. M. B. Reflexões Críticas sobre Processos de Aprendizagem de Universitários. 2013. Dissertação (Dissertação: Mestrado Profissional em Educação) - Universidade Federal de Lavras, p.51-63.

SOUZA, R. A. Telecolaboração e divergência em uma experiência de aprendizagem de português e inglês como línguas estrangeiras. Revista Brasileira de Lingüística Aplicada, Belo Horizonte, v. 3, n. 2, p. 73-96, 2003.

STERN, H. H. What can we learn from the good language learner? Canadian Modern Language Review, 34, p. 304-318, 1975.

TELLES, J. A. Learning foreign languages in Teletandem: Resources and strategies. DELTA, v. 31, p. 603-632, 2015.

TELLES, J. A. Teletandem: Metamorfoses impostas pela tecnologia sobre o ensino de línguas estrangeiras. In: (Org.). Teletandem: um contexto virtual, autônomo e colaborativo para aprendizagem de línguas estrangeiras no século XXI. Campinas: Pontes Editores, 2009, p. 63-74.

TELlES, J. A. Projeto Teletandem Brasil: línguas estrangeiras para todos - ensinando e aprendendo línguas estrangerias in-tandem via MSN Messenger. Faculdade de Ciências e Letras de Assis, UNESP, 2006. Disponível em: http://www.Teletandembrasil.org/site/docs/TELETANDEM_BRASIL _completo.pdf 
TELLES, J. A.; VASSALLO, M. L. Foreign language learning intandem: Teletandem as an alternative proposal in CALLT. The ESPecialist, v. 27, n. 2, p. 189-212, $2006 .$.

THORNE, S. L. Pedagogical and praxiological lessons from internetmediated intercultural foreign language education research. In: BELZ, J. A.; THORNE, S. L. (Eds.). AAUSC 2005: Internet-mediated intercultural foreign language education. Boston: Thomson Heinle, 2006.

VASSALLO, M.L.; TELLES, J. A. Foreign language learning intandem: Theoretical principles and research perspectives. The ESPecialist, v. 27, n. 1, p. 83-118, 2006.

VILAÇA, M. L. C. A importância de pesquisas em estratégias de aprendizagem no ensino de línguas estrangeiras. Cadernos do CNLF (CiFEFil), v. 15, p. 208-220, 2010.

VYGOTSKY, L. S. A formação social da mente. São Paulo: Martins Fontes, 1991.

WHITE, C. Language Learning Strategies in Independent Language Learning: An Overview. In: HURD, S.; LEWIS, T. Language learning strategies in independent settings. Bristol: Multilingual Matters, 2008, p. 3-24.

WILLIAMS M.; BURDEN, R.L. How does the learner deal with the process of learning? In: . (Org.). Psychology for language teachers. 6 ed. Cambridge: Cambridge University Press, 2002. p. 143166.

ZARE, P. Language learning strategies among EFL/ESL learners: a review of literature. International journal of humanities and social science, v. 2, p.162-169, 2012.

Recebido em: 13/06/2019 Aceito em: 25/11/2019 
Estratégias de aprendizagem no Teletandem...

Title: Learning strategies in Teletandem: what do English learners claim to do to learn in that context? 